\title{
Comparison of Economic Performance of Three Trade Free Zones in Iran (Kish, Gheshm,
} Chabahar)

\section{Ezzatollah Asgharizadeh}

Associated Professor of Dept. of Industrial Management, University of Tehran, Tehran, Iran, asghari@ut.ac.ir

\author{
Mehdi Ajalli \\ Corresponding Author: Ph.D Candidate of Industrial Management, University of Tehran, Tehran, \\ Iran, mehdiajalli2010@gmail.com
}

Mansoor Momeni

Professor of Dept. of Industrial Management, University of Tehran, Tehran, Iran, mmomeni@ut.ac.ir

\begin{abstract}
Free zones (Export Processing Regions) with their special Functions including assisting export development and making new job opportunities can be of major help to economy of countries. Present paper aims at comparing economic performance of three free trade zones of Iran, Kish, Gheshm and Chabahar during first ten years of their activities (1973 to 2004) using four techniques of operational research, SAW (Simple Additive Weighting), TOPSIS (Technique for Order-Preference by Similarity to Ideal Solution), ELECTEER (Elimination et Choice Translating Reading) and Taxonomy and taking economic goals of these zones as indices. To this end, economic goals of these zones, that is attracting foreign and internal investment, making new job opportunities, enhancing value of export from these zones and their ability to attract internal and foreign tourists were considered as research indices. Results obtained showed that free zone of Gheshm had a better performance compared to two other zones and this is due to significant difference of its export value compared to other zones, with regard to the available statistics and the said indices. Kish and Chabahar respectively followed it.
\end{abstract}

Keywords: Performance assessment, free trade zone, Kish, Gheshm, Chabahar, SAW, ELECTRE، TOPSIS, TAXONOMY

\section{Problem statement}

In today's world and considering rapidly increasing trend of globalization and elimination of economic borders between countries and intense competition among multinational companies and governments supporting them, it can be inferred that power of communities is in fact dependent to their economic power and political efforts are in fact headed towards economic goals, enhancement of well-being and wealth of their people. After Iran joined World trade organization and opened its borders to imported goods, not attending international trade arena in full power through making correct economic decisions and reliance on internal resources and production power and using privileges paves the way for final selfdestruction. To this end and to facilitate export of different kinds of products produced inside the country and importing capital goods required for internal production, government of Islamic republic of Iran started establishing the three said free trade zones in early 90 s to take necessary steps as to achieving the set goals. After ten years and after efficiency and effectiveness of the established zones became clear and after feeling need to have new zones, plans for establishing three new free trade zones (Arvand, Aras, Anzali) were approved by Islamic Parliament and thereby, covered free trade zones of North and South parts of Iran. If these zones have successful performance Iran can enjoy the following privileges:

- Facilitation and enhancement of non-oil export (considering decrease in oil reserves and necessity of reliance of economy on renewable resources and using local human resources) [1].

- Raising foreign currency revenues of Iran and diversification of its resources

- Raising foreign investments 
- Making new job opportunities and helping development of these zones. On the contrary, if performance of these zones is diverted, excessive raise in imports from these zones puts their performance on the trail against national interests and this disadvantage is added to destruction of current opportunities.

Considering opportunities facing Iran including its strategic geographical location and possibility of taking advantage of conditions and regional political-economic competition, accessing high seas and main regional consumer markets in north and south of Iran and relative advantage in production and transit of special goods, it is not far reaching to expect that the said zones will have successful performance. But the important point to be clear is that with regard to huge investments made in these zones, can they enjoy expected and predicted performance or not. If the answer to this question is positive, what is suggested to continue the path and to enhance them? But if the answer is negative, what are the reasons behind lack of success and what solutions are suggested to improve the situation.

\section{Introduction}

Free trade zone and its new definition "export processing zone" is a small geographical location inside a country and its goal is to attract export-oriented industries though offering desired conditions for trade and investment. Free zones in developing countries are distinguished from other parts of economy of the related country in such areas as conditions, rules and regulations regarding export and import, infrastructures, etc. and generally, are established near international airports and ports [2]. But sometimes a difference is put between free trade zone and export processing zone. Free zones are considered as traditional zones having long history but export processing zones are considered as new phenomena with goal of increasing export. Present paper puts no difference between these zones. Record of establishing free zones in Iran goes back to the year 1991. During this year, Islamic Parliament approved plan for establishing Kish, Gheshmand Chabahar free trade zones and ten years after that in 2003, decided to establish three other zones (Arvand, Anzali and Aras). With regard to privileges these zones potentially bring to Iran, this measure was worth a while. But unfortunately, it seems that no sufficient attention has been paid to them on the part of governments regarding investment, managerial support and creating infrastructures and on the part of researchers regarding identifying problems and challenges facing them and offering suggestions as to make an improvement [3].

Governments generally have the following goals when establishing such zones:

- Creating foreign currency revenue through improving export of non-traditional goods and diversifying foreign currency revenue sources of the country

- $\quad$ Attracting foreign investments

- Making new job opportunities and reducing problems resulting from unemployment

- Importing new technologies adapted to internal circumstances

- Disseminating knowledge, demonstration effects and enhancing competiveness of local agencies [4].

Other objectives may be considered when regarding for conditions inside each country. Among these objectives are eliminating deprivation and enhancing wellbeing of local people. To achieve these goals, some strategies have been codified for managing free zones:

- Issuing certificate of importing raw materials, intermediate data and capital goods exempted from customs

- Less unnecessary formalities and flexibility of labor laws to encourage investments

- Tax exemption

- Offering communication services and equipment above average limit of host economy

- Possibility of joint investment of local and international agencies

With regard to technology transfer, the point to be mentioned is that transferring technical knowledge and technology transfer to the country is conducted in three ways: 
1. By cooperation among companies having new technologies and local companies (or natural persons) regarding knowledge transfer and main sections of production process to Iran.

2. Training local human resources and assigning managerial positions to them in host country

3. Establishing technical relation and resources transfer among transferor country and host country

Through studying common structure of activity in the free zones of Iran and free zone of Gheshm, it becomes clear that majority of activities suggest localization of capital in labor intensive, small (mainly) and low technology industries and establishment of assembly section (or packaging section) in these zones and even relatively heavy industries have had no significant dependence to foreign technologies. Therefore, attracting new technology, even in presence of a structure such as the one existing in free zones right now, is inconsistent with what is expected [5].

Free zones approved to be established in 1993 were Kish, Gheshm and Chabahar. At first, these zones were deprived of basic facilities and necessary infrastructures for implementing these huge plans and developments conducted in them, although not significant compared to what has been expected, their progress is a huge step since their first days. Investments made in these zones up to 2003 have amounted to IRR. 7586 Billion. This amount of investment includes civil and current expenses and expenses covered by free zone agencies in affiliated companies and institutes. Having such capabilities as very desirable geographical position, vast territory, oil and gas reserves, plenty of local capable human resources, diverse resources and raw materials on national level and acceptance on the part of local people in all zones, closeness to foreign consumer markets in Persian Gulf region and accessing high seas which facilitates transit of goods to different regions, have paved the way to their ever more development and progress [6].

As previously mentioned, free zones call for special attention due to the fact that they provide for national interest on national level. But unfortunately, researches published till now are so thin. It may be said that the most important reason of this issue is lack of information sources published by official authorities in this regard. Firstly, it is notable to consider a study conducted in 1995 as a thesis. This study assesses accuracy of positioning of commercial-industrial free zones in Iran and using such operational research techniques as minimizing expenses of transportation, human resources and general regional factors, maximizing profit, factor analysis, positioning studies and pattern of studying location of market and after scoring all cities of Iran, considers four zones of Anzali, Sari, Bandarabbas and Boushehr for commercial purposes and assigns commercial function to Bandarabbas. Other researches have been conducted on "factors affecting attraction and expansion of investment in Gheshm free zone' and 'studying status of relative advantage of labor intensive industries in Gheshm free zone". But considering initial objectives, have finally resulted in no tangible conclusion with regard to performance improvement [7].

\section{Research Methodology}

Present paper is in fact a survey study and attempts to compare economic performance of Kish, Gheshm and Chabahar free zones using four techniques naming taxonomy, Topsis, Saw and Electree. The reason for choosing these three zones is that they have been established at the same time and have the same record and this provides for possibility of ranking them. Due to special conditions and more tourist attractions compared to two other zones, Kish has attracted more attention and more investments made in that have resulted in its better performance in some areas. Indices considered in this regard are generally the same goals expected from free zones. Although in their choosing, accessing the required data has been considered, comparing a ten year period (from 1994 to a decade after that in 2004) is included as well. After the first decade of establishment of these zones, a turning point in their history was observed, as at the end of this ten year period, government started establishing new zones through considering weak points and strengths of their performance. Indices chosen in this regard are as follows: internal investment attracted by each zone in IRR. Billion, foreign investment attracted in Dollar Million, value of export in a thousand dollars, making job opportunities in thousand people which due to having no access to information of the years 1991 to 2004, only covers statistics of the years 1993 to 2001 (this is due to the fact that comparing three zones based on one index and the same information, is of no harm to the desired goal). Number of internal and foreign travelers attracted to free zones (in thousand people) is due to effect of such factors in helping development of the zones. Technology could be considered as an important factor which due to not having any index for measuring that in three said zones is omitted from this set of indices. This way, decision making matrix is prepared as follows: 
Table 1: Figures of Free Zones' Economic Performance from 1993-2004

\begin{tabular}{|l|l|r|r|r|r|r|}
\hline $\begin{array}{l}\text { Number of } \\
\text { Foreign } \\
\text { Travelers }\end{array}$ & $\begin{array}{l}\text { Number of } \\
\text { Internal } \\
\text { Travelers }\end{array}$ & $\begin{array}{l}\text { Making job } \\
\text { Opportunities }\end{array}$ & $\begin{array}{l}\text { Foreign } \\
\text { Investment }\end{array}$ & $\begin{array}{l}\text { internal } \\
\text { investment }\end{array}$ & $\begin{array}{l}\text { value of } \\
\text { export }\end{array}$ & Zone \\
\hline Kish & 19466 & 23886 & 1647 & 10.5 & 10684 & 529.49 \\
\hline Gheshm & 115312 & 4725 & 1095 & 26.5 & 8907 & 447.86 \\
\hline Chabahar & 2326 & 1382 & 59 & 8.5 & 8571 & 2.88 \\
\hline
\end{tabular}

Four following techniques are among operational research techniques and provide for comparing various options according to a number of indices and are considered as a part of multivariate decision making (MADM) models. MADM techniques are divided into compensatory and non-compensatory up ones. Compensatory models include methods which allow for transfer between indices. For example, weaknesses of an index can be compensated by strength of another index. Noncompensatory models include such methods that do not allow for transfer between indices. Therefore, each index is considered alone and comparison is conducted index by index. Non-compensatory models are divided into three groups: Concordance sub group; scoring sub group and scoring sub group. From the first class, Electree technique, from the second one, Topsis and from the third class, Saw techniques are used.

SAW Technique: According to this technique, normalizing figures was conducted using scaling up method and weight of each index was obtained using Shannon's Entropy Technique. For final ranking of normalized figures, each index was multiplied by the obtained weight. Table of normalized figures and weight of indices and ranking of figures is as follows:

(Table 2):

Table 2: Normalized Figures and Weight of Indices Matrix

\begin{tabular}{|l|r|r|r|r|r|r|}
\hline & $\mathrm{X} 1$ & $\mathrm{X} 2$ & $\mathrm{X} 3$ & $\mathrm{X} 4$ & $\mathrm{X} 5$ & $\mathrm{X6}$ \\
\hline Kish & 0.168 & 1 & 1 & 0.396 & 1 & 0.845 \\
\hline Gheshm & 1 & 0.197 & 0.664 & 1 & 0.833 & 1 \\
\hline Chabahar & 0.02 & 0.057 & 0.035 & 0.32 & 0.802 & 0.005 \\
\hline w & 0.175 & 0.149 & 0.172 & 0.089 & 0.187 & 0.226 \\
\hline
\end{tabular}

Normalized figures according to linear scaling up method: $P_{i j}$

$$
\begin{aligned}
& A_{i j}=\frac{a_{i j}}{\operatorname{Maxa}_{i j}} \\
& \mathrm{E}=\frac{1}{\ln m} \sum\left(P_{i j} \ln P_{i j}\right)
\end{aligned}
$$




$$
\mathrm{w}=d_{j}=1-E_{j} \frac{d_{j}}{\sum d_{j}}
$$

$S_{1}=0.613 \quad S_{2}=0.789 \quad S_{3}=0.198$

As can be seen, according to SAW technique and according to the weights obtained for options, performance of Gheshm is better than Kish and performance of Gheshm is more desirable than Chabahar.

Topsis technique: Many papers have proposed analytical models as aids in conflict management situations. Among the numerous approaches available for conflict management, one of the most prevalent is multi-criteria decision making. Decision-making problem is the process of finding the best option from all of the feasible alternatives. In almost all such problems the multiplicity of criteria for judging the alternatives is pervasive. That is, for many such problems, the decision maker wants to solve a multiple criteria decision making (MCDM) problem. In classical MCDM methods, the ratings and the weights of the criteria are known precisely $[8,9,10]$ MCDM may be considered as a complex and dynamic process including one managerial level and one engineering level [11].The managerial level defines the goals, and chooses the final "optimal" alternative. The multi-criteria nature of decisions is emphasized at this managerial level, at which public officials called "decision makers" have the power to accept or reject the solution proposed by the engineering level. These decision makers, who provide the preference structure, are "off line" from the optimization procedure done at the engineering level [12]. The engineering level of the MCDM process defines alternatives and points out the consequences of choosing any one of them from the standpoint of various criteria. This level also performs the multi-criteria ranking of alternatives [13].

Technique for order performance by similarity to ideal solution (TOPSIS), one of the known classical MCDM methods, was first developed by Hwang and Yoon [14] for solving a MCDM problem. It bases upon the concept that the chosen alternative should have the shortest distance from the positive ideal solution and the farthest from the negative ideal solution. In the process of TOPSIS, the performance ratings and the weights of the criteria are given as crisp values.

Under many conditions, crisp data are inadequate to model real-life situations. Since human judgments including preferences are often vague and cannot estimate his preference with an exact numerical value.

Normalized figures of indices were obtained according to Euclidian descaling method. Data were weighted according to Shannon's Entropy technique, dividing measurements of each option was calculated and relative closeness of each option to the ideal answer was obtained (Relation 1). Finally, the matrix shows that what normalized figures of each data and finally, weight of indices are and what are ranking of figures (Relation 2).

Table 3: Normalized figures and weight if indices matrix

\begin{tabular}{|l|r|r|r|r|r|r|}
\hline & $\mathrm{X} 1$ & $\mathrm{X} 2$ & $\mathrm{X} 3$ & $\mathrm{X} 4$ & $\mathrm{X} 5$ & $\mathrm{X6}$ \\
\hline Kish & 0.166 & 0.974 & 0.832 & 0.353 & 0.654 & 0.806 \\
\hline Gheshm & 0.985 & 0.193 & 0.55 & 0.89 & 0.545 & 0.682 \\
\hline Chabahar & 0.019 & 0.05 & 0.029 & 0.285 & 0.524 & 0.004 \\
\hline w & 0.241 & 0.205 & 0.195 & 0.092 & 0.051 & 0.216 \\
\hline
\end{tabular}




$$
\begin{aligned}
& d_{i}^{+}=\sqrt{\sum\left(V_{i j}-V_{i}^{*}\right)^{2}} \\
& \mathrm{~d}_{i}^{-}=\sqrt{\left(\sum V_{i j}-V_{i}^{-}\right)^{2}}
\end{aligned}
$$

$$
\mathrm{C}=\frac{d_{i}^{-}}{d_{i}^{-}+d_{i}{ }^{+}}
$$

$\mathrm{C}_{1}=0.607$

$$
\mathrm{C}_{2}=0.625
$$

$\mathrm{C}_{3}=0$

Therefore, according to Topsis techniques, Gheshm has a better performance than Kish and performance of Kish is better than Chabahar, though Kish and gheshm, have close performances.

Electree based Scoring: According to this technique, normalized matrix is calculated in the same way as TOPSIS. Then, concordant and not concordant sets are obtained for each index and the following matrices. Concordant set of $A_{k, l}$ includes indices in which, option $\mathrm{k}$ is superior to option I and not concordant set includes options in which, option $\mathrm{k}$ is not preferred to option I.

$$
N I_{k, l}=\frac{\operatorname{Max}\left|V_{k j}-\bar{V}_{l j}\right|}{\operatorname{Max}\left|V_{k j}-V_{l j}\right|} \quad I_{k, l}=\sum w_{j}
$$

$$
\overline{N I}_{k, l}=\frac{\operatorname{Max}\left|V_{k j}-\bar{V}_{l j}\right|}{\operatorname{Max}\left|V_{k j}-V_{l j}\right|} \bar{I}=\frac{\sum I_{k, l}}{m(m-1)}
$$

Number of options: $m$

Two $3 * 3$ matrixes are formed according to the following instruction: 


$$
\begin{aligned}
& I_{k, l} \geq \bar{I} \rightarrow f_{k m l}=1 \\
& I_{k, l}<\bar{I} \rightarrow f_{k, l}=0 \\
& N I_{k, l} \leq \bar{N} I \rightarrow g_{k, l}=1 \\
& N I_{k, l}>\bar{N} I \rightarrow g_{k, l}=0
\end{aligned}
$$

Final comparison is achieved based on matrix obtained from multiplication of two matrices (matrix 1) resulting from the following matrices. Results of brief operation are as follows:

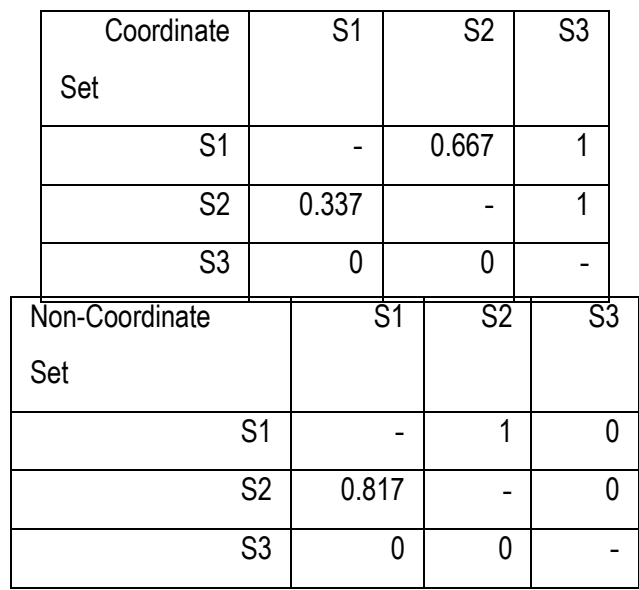

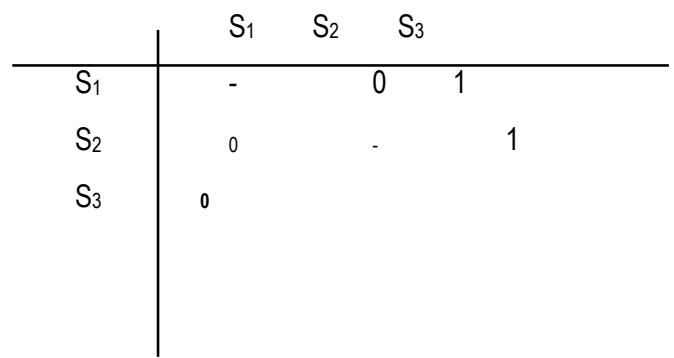

(Matrix 1)

Therefore, considering the fact that final preferences matrix of performance for Kish and Gheshm was obtained equally, in final scoring, each one can be considered as $1^{\text {st }}$ rank and Chabahar follows them.

$$
\mathrm{S} 1=\mathrm{S} 2>>\mathrm{S} 3
$$

\section{Scoring performance of free zones according to Taxonomy technique}

Table 4 


\begin{tabular}{|r|r|r|r|r|r|r|}
\hline & X1 & X2 & X3 & X4 & X5 & X6 \\
\hline S1 & 19466 & 23886 & 1647 & 10.5 & 10684 & 529.49 \\
\hline S2 & 115312 & 4726 & 1095 & 26.5 & 8907 & 447.86 \\
\hline S3 & 2326 & 1382 & 59 & 8.5 & 8571 & 2.88 \\
\hline \hline- & 45701 & 9997.6 & 933.6 & 18.6 & 9387.3 & 326.74 \\
$X$ & & & & & & \\
\hline$\sigma$ & 60890.71 & 12143.2 & 806.2 & 10.7 & 1135.5 & 283.4 \\
\hline
\end{tabular}

Normalized figures table according to the formula for calculating normal standard figure (Z) is as follows:

Table 5

\begin{tabular}{|c|c|c|c|c|c|c|c|}
\hline & $\mathrm{X} 1$ & $\mathrm{X} 2$ & $\mathrm{X} 3$ & $\mathrm{X} 4$ & $\mathrm{X} 5$ & $\mathrm{X} 6$ & gi \\
\hline S1 & .75 & 1.14 & .88 & -.75 & 1.14 & .71 & 10.67 \\
\hline S2 & 11.43 & -.43 & .15 & .73 & -.42 & .42 & 2.54 \\
\hline S3 & -.71 & -.7 & -1.08 & -.94 & -.71 & -1.14 & 12.68 \\
\hline & & & & & & & $\mathrm{g}=8.63$ \\
\hline
\end{tabular}

$\mathrm{Z}=\frac{x_{i}-x}{\sigma}$

At this level, in order to omit inconsistent options, through calculating Euclidean distance of each two couples, upper bound and lower band were determined with 95\% confidence and the result shows that none of the options can be omitted (homogenization operation has shown). Numbers inside matrix are Euclidean distance of each two couples.

Table 6

\begin{tabular}{|c|c|c|c|c|}
\hline & $\mathrm{S} 1$ & $\overline{\mathrm{S} 2}$ & S3 & $\mathrm{Ri}$ \\
\hline S1 & - & 10.93 & 4.02 & 4.02 \\
\hline S2 & 10.93 & - & 12.45 & 10.93 \\
\hline S3 & 4.02 & 12.45 & - & 4.02 \\
\hline & & & & $\bar{R}=6.32$ \\
\hline
\end{tabular}

$S^{2}=15.915 \quad S=3.98$

$L=6.32-2(3.98)=-1.65$

$\mathrm{U}=6.32+2(3.98)=14.29$ 
Now after referring to normalized figures, standard deviation $\mathrm{gi}_{\mathrm{i}}$ can be calculated and through that and by considering formula of ranking options, they are ranked. Thereby, if variable $y_{i}$ is considered for ranking options, the following results will be obtained. The option having less $y_{i}$ is better and this shows that performance of Gheshm free zone is better than Kish and Kish is better than Chabahar.

$$
Y_{i}=\frac{g_{i}}{-}
$$

$\mathrm{Y}_{1}=0.55 \quad \mathrm{y}_{2}=0.131 \quad \mathrm{y}_{3}=0.65$

In conclusion, comparing performance results among different techniques is as shown in the following tables. According to Kaplan method, results of performances are compared. In this method, table for win and lose of each option compared to other options is prepared and final score is obtained from difference of wins and loses. Considering higher different of wins and losses for Gheshm free zone compared to other zones, this zone has been collectively of the best performance and Kish and chabahar respectively follow that.

Table 7: Comparison of zones' ranks in different techniques

\begin{tabular}{|l|r|r|r|r|}
\hline & SAW & TOPSIS & TAXONOMY & ELECTRE \\
\hline Kish & 2 & 2 & 2 & 1.5 \\
\hline Gheshm & 1 & 1 & 1 & 1.5 \\
\hline Chabahar & 3 & 3 & 3 & 3 \\
\hline
\end{tabular}

Table 8: General ranking according to Kaplan method.

\begin{tabular}{|l|r|r|r|r|}
\hline & Kish & Gheshm & Chabahar & \multicolumn{2}{|c|}{$\begin{array}{c}\text { different of wins and } \\
\text { losses }\end{array}$} \\
\hline Kish & - & D & W & $2-1=1$ \\
\hline Gheshm & W & - & W & $2-0=2$ \\
\hline Chabahar & D & D & - & $0-2=-2$ \\
\hline
\end{tabular}

\section{Conclusion}

In one technique, Kish and in in three techniques, Gheshm gained $1{ }^{\text {st }}$ place and Chabahara was recognized as a zone with the weakest performance as it gained third rank in all indices. Through careful investigation of results obtained it can be seen that better performance of Gheshm is its higher rate of export value compared to other zones. This difference is so significant that has made this zone relatively successful and has affected capabilities of Kish in some indices such as attracting internal and foreign investment. In 2004, free zone development plan was codified based on strategy of codifying division plans of $4^{\text {th }}$ development plan of Iran towards "national interests" of this country. This plan is to visualize movement path of six free zones including Kish, Gheshm, Chabahar, Aras, Arvand, Anzali and to detail goals of progress in these zones. In free zone development plan, challenges of development have been detailed along with solutions as to developing each zone. But, up to 2007, this plan wan not discussed in cabinet and it seems that no success is going o come out of continuing this process for free zones. Specifically, in Iran, competition of these zones with zones located in Persian Gulf area such as Hamriye and Fajiye which are trying to gain international-level performance is an issue and weaknesses and strengths of each zone must be considered when determining special missions for each zone. This study is a starting point 
for publishing other studies regarding free commercial and industrial zones as well as special economic regions of Iran and through investigating different aspects of these zones, their performance is enhanced. It is recommended that similar studies are conducted through considering investments and expenses consumed relative to performance in order that efficiency and effectiveness of managerial decisions and policies applied to each zone become clear. Moreover, researches on percentage of achieving predicted goals of each zone and identifying achieving or not achieving them must be conducted. Lack of statistics offered up to 2006 has limited studies to investigating performance of these zones up to the year 2004 and no more. Also, lack of statistics regarding investments made in each zone has resulted in not taking these figures into account when calculating and if these indices were measured based on expenses and investments, a good index for comparing managerial performance and efficiency of each zone would be formed. Statistics regarding making job opportunities of zones for the period of 1993-2001 were available and used. Another limitation, as previously mentioned, was lack of a generally accepted index for measuring "technology transfer" which if available, could make a full comparison possible.

\section{References}

[1] http://www.qeshm.ir/?Lang=fa\&Page $=40-22$

[2] http://www.irtp.com/farsi/data.asp?address=references/statistics

[3] http://www.itsr.ir

[4] http://www.unctad.org/Templates/Search.asp?intltemID=2068\&lang=1\&frmSearchStr EPZ \& frmCategory=all\&section=whole

[5] UNCTAD. (1993). export processing foreign zones for sub-Saharan Africa.UNCTAD,EDCD,255

[6] http://www.tarkhis.net/modules.php?name=News\&file=article\&sid=348.-

[7] Yoon, K Paul. Hwang, Ching Lai. (1995). Multiple Attribute Decision Making an Introduction (Quantitative Applications in the Social Sciences .California. Sage Publication.

[8] Chen, C. T., 2000. A fuzzy approach to select the location of the distribution center, Fuzzy Sets and Systems, $118,(1), 65-73$.

[9] Zimmermann H.-J., 1987. Fuzzy Sets, Decision-making and Expert Systems, Kluwer, Boston.

[10] Hsu H.M., Chen C.T., 1997. Fuzzy credibility relation method for multiple criteria decision-making problems, Information Sciences 96, 79-91.

[11] Teghem J., C. Delhaye Jr., Kunsch P.L., 1989. An interactive decision support system (IDSS) for multicriteria decision aid, Mathematics Computer Modeling 12:10/11, 1311-1320.

[12] Mahmoud A., Sinna Abo., Azza H. A., 2005. Extensions of TOPSIS for multi-objective large-scale nonlinear programming problems, Applied Mathematics and Computation, Volume 162, Issue 1, 4, Pages 243-256

[13] Lee E.S. LiR.L., 1988. Comparison of fuzzy numbers based on the probability measure of fuzzy events, Computer Mathematics Application 15, 887-896.

[14] Hwang C.L., Yoon K., 1981. Multiple Attributes Decision Making Methods and Applications, Springer, Berlin Heidelberg. 
